\title{
Bioproduction of Sorbicillin Derivatives from Marine Trichoderma sp.
}

Ahmed Abdel-Lateff

Department of Pharmacognosy, Faculty of Pharmacy, Minia University, 61519 Minia, Egypt. Fax: 002-0 86-236-90-75. E-mail: aabelazim@yahoo.co.uk

Z. Naturforsch. 63 c, 631-635 (2008); received November 27, 2007/February 27, 2008

The variability of sorbicillin derivatives production by marine Trichoderma sp., isolated from the sponge Agelas dispar J., was studied using six different culture media to find a good medium for biomass production, particularly of trichodimerol, bislongiquinolide and bisvertinol. A simple and rapid convenient method for identification, quantification and validation of the sorbicillin derivatives in ethyl acetate extracts has been applied by using RPHPLC coupled with diode array detection.

Key words: Trichoderma sp., Sorbicillin Derivatives, Trichodimerol

\section{Introduction}

Marine micro-organisms, particularly fungi, have recently been utilized as a new source of novel bioactive secondary metabolites (König and Wright, 1996). Natural products isolated hitherto from cultures of marine fungi are in many cases similar to those of terrestrial fungi (König and Wright, 1999), but marine fungi display highly specific adaptations to the marine environment in- cluding the production of unique secondary metabolites (Höller et al., 2000).

Fungi of the genus Trichoderma are widely distributed as soil and aquatic inhabitants and have been investigated for the production of bioactive metabolites such as sorbicillin and vertinolide (Andrade et al., 1992; Sperry et al., 1998). Sorbicillin derivatives (Fig. 1), particularly trichodimerol, are structurally unusual natural products, discov-

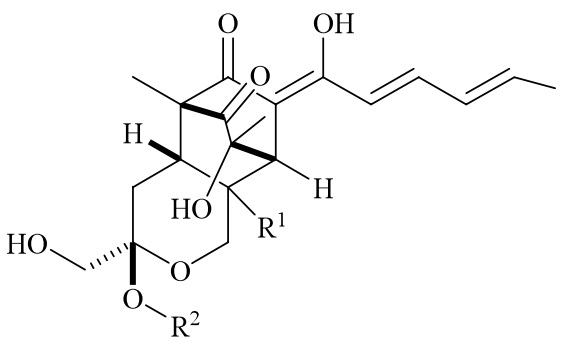

Trichodermanone A (1): $\mathrm{R}^{1}=\alpha-\mathrm{OH}, \mathrm{R}^{2}=\mathrm{CH}_{3}$ Trichodermanone C (2): $\mathrm{R}^{1}=\beta-\mathrm{OH}, \mathrm{R}^{2}=\mathrm{H}$<smiles>C/C=C/C=C/C(=O)C1=C(O)[C@]2(C)[C@H]3C(C(=O)/C=C/C=C/C)=C(O)C(C)=C(O)[C@@]3(C)O[C@]2(C)[C@@H](O)C1</smiles>

Bisvertinol (4)
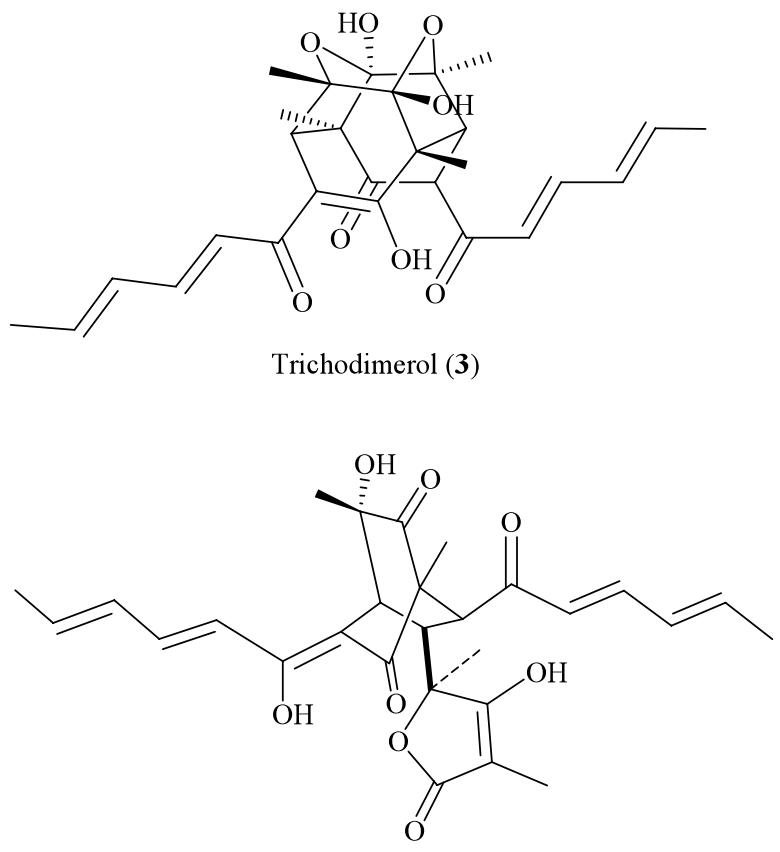

Bislongiquinolide (5)

Fig. 1. Chemical structures of the reference substances used in this study. 
Table I. Components of the media M1-M6 in $3 \mathrm{~L}$.

\begin{tabular}{|c|c|c|c|c|c|c|}
\hline Component & M1 & M2 & M3 & M4 & M5 & M6 \\
\hline Biomalt $^{\mathrm{a}}$ & 50 & 50 & 50 & $50^{\mathrm{d}}$ & & \\
\hline Glucose & & & 10 & 10 & 0.5 & 2.0 \\
\hline Glycerol & & & & & 1.0 & \\
\hline Peptone from casein ${ }^{b}$ & & & & & 0.5 & \\
\hline Yeast extract & & & & & 0.3 & 0.5 \\
\hline Malt extract & & & & & 0.5 & 0.5 \\
\hline $\mathrm{K}_{2} \mathrm{HPO}_{4}$ & & & & & & 0.5 \\
\hline $\mathrm{MgSO}_{4}$ & & & & & & 0.05 \\
\hline Distilled water (DW) & 1000 & & 1000 & & 100 & \\
\hline $\begin{array}{l}\text { Artificial sea water } \\
(\text { ASW })^{c}\end{array}$ & 1000 & 1000 & & & 100 & \\
\hline
\end{tabular}

a Obtained from VillaNatura Gesundheitsprodukte GmbH, Kirn, Germany.

b Obtained from Fluka GmbH, Buchs, Switzerland.

c ASW was freshly prepared, and the chemicals were obtained from the companies as mentioned in Höller et al. (1999).

d Estimated as $\mathrm{g} / \mathrm{L}$ of the medium.

ered from several species of marine and terrestrial fungi, and inhibit the lipopolysaccharide-induced production of tumour necrosis factor alpha (TNF$\alpha$ ) in human monocytes (Nicolaou et al., 1999, 2000). The main goal of the current work was to study the effects of different media on the sorbicillin derivatives produced by Trichoderma sp., particularly on trichodimerol and bisvertinol (Fig. 1).

On these bases, six media with different composition (M1-M6) were studied. Trichoderma sp., a marine fungal isolate, was cultivated on these liquid media. Two of which were published as media for similar compounds production (Abe et al., $1998 \mathrm{a}, \mathrm{b})$ and the remaining four media were supposed (Table I). The ethyl acetate extracts were analyzed using reversed phase HPLC coupled with diode array detection (DAD).

\section{Results and Discussion}

The analysis of the total extract obtained from the cultivation of Trichoderma sp., as published by Neumann et al. (2007), has been done using HPLC coupled with DAD and LC/ESIMS. The isolation, purification and structural elucidation of the reference compounds had been published by Neumann et al. (2007).

The long gradient chromatographic separation time of $115 \mathrm{~min}$ of reversed phase HPLC combined with DAD allowed a high sample throughput. Eleven peaks in the total extract were detectable at $360 \mathrm{~nm}$ (Fig. 2). These results are in good agreement with the results obtained from the LC/ ESIMS analysis.

The standard curves of the five compounds were measured by using the same HPLC method at 10 , $3,2,1,0.5 \mu \mathrm{g} / \mathrm{mL}$ (Fig. 3). It is clear that the HPLC spectrum of each extract showed different peaks, and it is difficult to study all peaks due to the shortage of the reference samples.

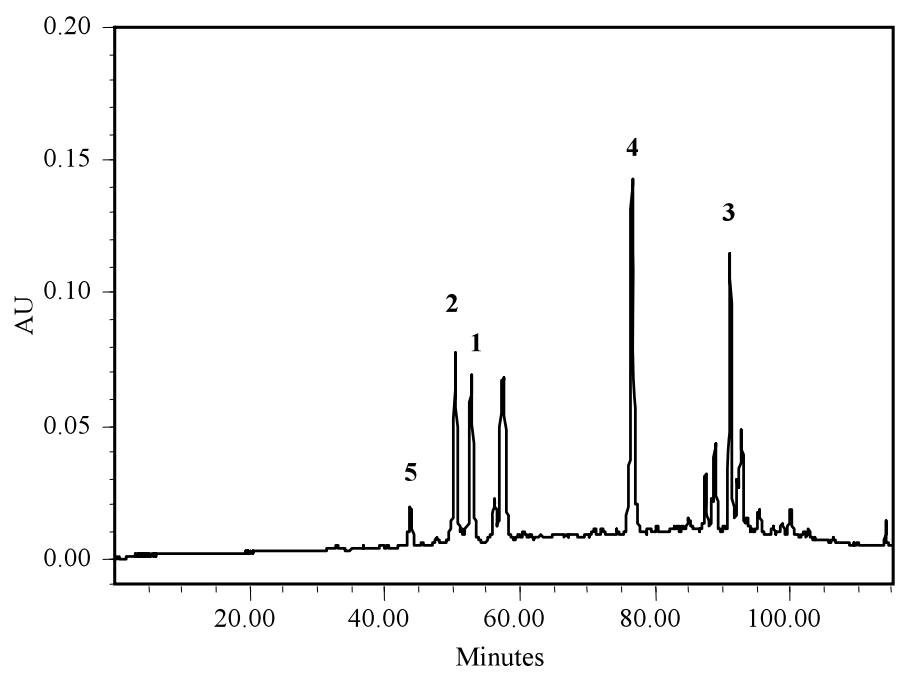

Fig. 2. HPLC chromatogram of the total extract of Trichoderma sp. UV detection at 360 nm. 1, Trichodermanone A; 2, trichodermanone C; 3, trichodimerol; 4, bisvertinol; 5, bislongiquinolide. 

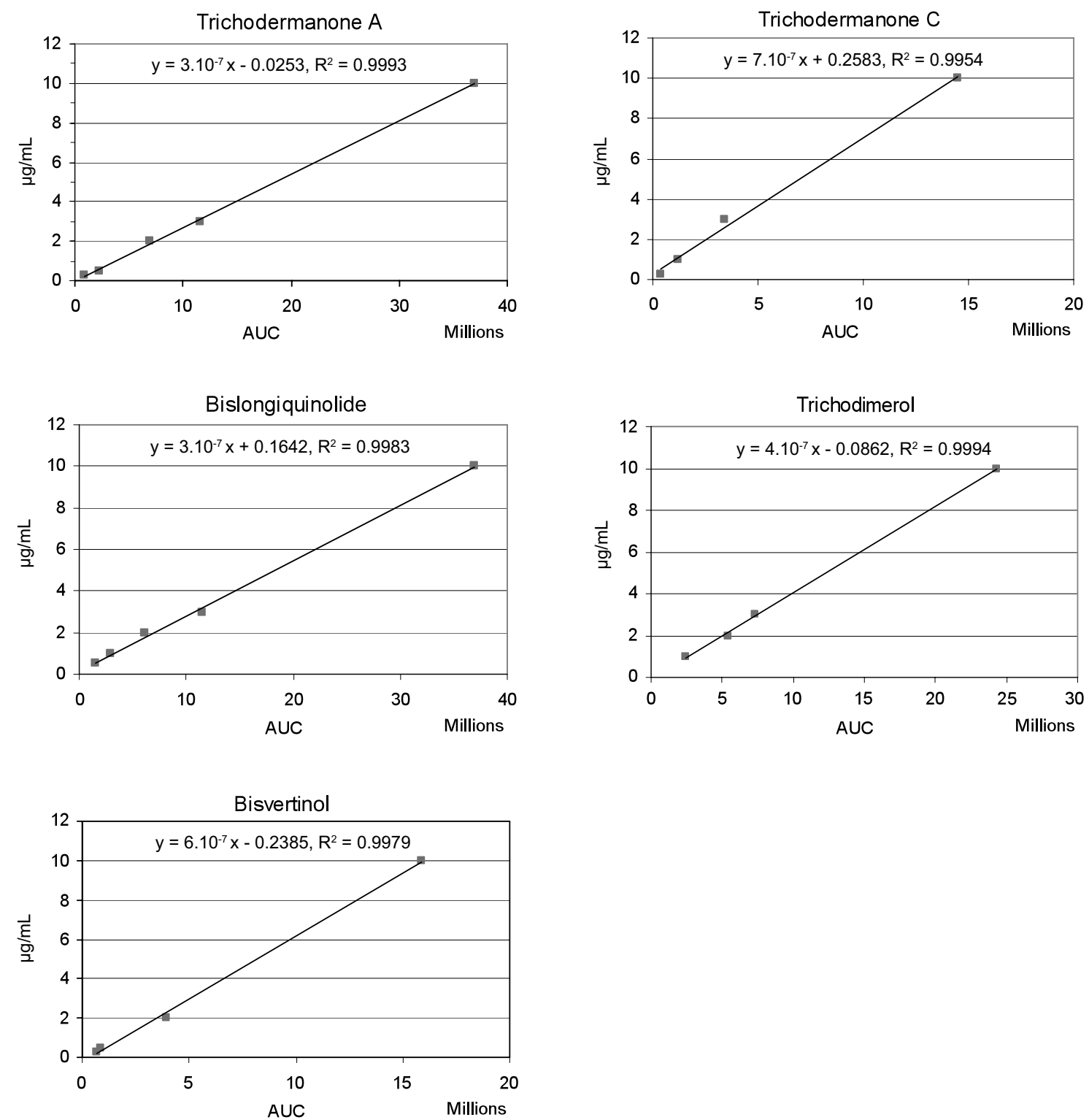

Fig. 3. Standard curves of the sorbicillin derivatives. AUC is the area under the curve calculated mechanically.

Both the retention time of the reference compounds which were analyzed separately and major peaks in the total extracts led to a proper selection of the reference compounds. Medium 1 (M1) spectrum at $360 \mathrm{~nm}$ showed three peaks $(\mathrm{Rt}=26.8$, $58.1,84.4 \mathrm{~min})$. The first peak was not identified due to unavailable authentic samples as well as the isolated amount was not sufficient for analysis. The remaining two peaks $(\mathrm{Rt}=58.1,84.4 \mathrm{~min})$, were confirmed by co-injection of trichoderman- one A and trichodimerol, respectively. The spectrum of medium 1 at $300 \mathrm{~nm}$ showed six peaks $(\mathrm{Rt}=5.3,5.8,22.8,27.9,45.6,58.1 \mathrm{~min})$. The peaks at $\mathrm{Rt}=45.6 \mathrm{~min}$ and , $58.1 \mathrm{~min}$ were enhanced when bislongiquinolide and trichodimerol were co-injected. Medium 2 (M2) spectrum at $360 \mathrm{~nm}$ showed four peaks $(\mathrm{Rt}=61.0,63.7,66.0,72.2 \mathrm{~min})$. The last peak was only identified by using the authentic sample through co-injection as bisvertinol. The spectrum of medium 2 at $300 \mathrm{~nm}$ showed 
three peaks $(\mathrm{Rt}=60.3,66.6,72.2 \mathrm{~min})$. The peak with $\mathrm{Rt}=72.2 \mathrm{~min}$ was enhanced when bisvertinol was co-injected. The remaining peaks were not identified due to lack of the authentic samples. Medium 3 (M3) spectrum, at both 300 and $360 \mathrm{~nm}$, showed only one peak $(\mathrm{Rt}=57.9 \mathrm{~min})$ which was identified and confirmed by co-injection of trichodermanone A. Medium 4 (M4) spectrum at $360 \mathrm{~nm}$ showed only one peak $(\mathrm{Rt}=56.2 \mathrm{~min})$ which was identified and confirmed by co-injection of trichodermanone A. The spectrum of medium 4 at $300 \mathrm{~nm}$ showed five peaks $(\mathrm{Rt}=5.8,6.2$, $24.1,43.3,56.2 \mathrm{~min})$. The peaks with $\mathrm{Rt}=43.3 \mathrm{~min}$ and 56.2 min were enhanced by co-injection of bislongiquinolide and trichodermanone $\mathrm{A}$, respectively. The remaining peaks were not identified due to lack of authentic samples. Medium 5 (M5) spectrum, at $360 \mathrm{~nm}$, showed seven peaks $(\mathrm{Rt}=$ 51.7, 56.1, 62.8, 67.1, 74.1, 78.4, $89.2 \mathrm{~min}$ ). Co-injection of the reference compounds identified $(\mathrm{Rt}=51.7,56.1,74.1,89.2 \mathrm{~min})$ trichodermanone $\mathrm{A}$ and $\mathrm{C}$, bislongiquinolide and trichodimerol. Studying the spectrum of medium 5 at $300 \mathrm{~nm}$ showed ten peaks $(\mathrm{Rt}=5.3,8.2,24.3,51.7,56.1$, $67.1,70.4,74.1,76.9,89.2 \mathrm{~min})$. The peaks with $\mathrm{Rt}=51.7,56.1,74.1$, and $89.2 \mathrm{~min}$ were enhanced by co-injection of trichodermanone $\mathrm{A}$ and $\mathrm{C}$, bislongiquinolide and trichodimerol, respectively. The remaining peaks were not identified due to lack of authentic samples. Medium 6 (M6) spectrum, at $360 \mathrm{~nm}$, showed only one peak $(\mathrm{Rt}=$ $52.2 \mathrm{~min}$ ) which was identified by co-injection of trichodermanone $\mathrm{C}$. The spectrum of medium 6 at $300 \mathrm{~nm}$ showed seven peaks $(\mathrm{Rt}=5.7,7.3,9.1$, 14.5, 24.7, 39.6, 52.2 $\mathrm{min})$. The peak with $\mathrm{Rt}=$ 52.2 min was enhanced when trichodermanone $\mathrm{C}$ was co-injected. Trichodimerol was produced by media 1 and 5 but in minute quantity. The remaining media produced other sorbicillin derivatives.

\section{Material and Methods}

\section{General}

HPLC analysis was performed on a Waters apparatus (four solvent delivery systems model 600 controller pump, automatic sample injector model 717, and photodiode array detector model 996) using an RP-HPLC column (XTerra RP-18, $5 \mu \mathrm{m}$, $250 \times 4.6 \mathrm{~mm}$, Waters). LC/ESIMS experiments were carried out on an API 2000, Triple Quadrupole LC/MS/MS, Applied Biosystems/MDS Sciex instrument equipped with an Agilent 1100 Serie diode array detector. The materials of the media were purchased from international companies (Fluka and Merck).

The fungus, Trichoderma viride Persoon in Römer (Hypocreaceae, Ascomycota, 193E61, 54) (Persoon et al., 1794), was isolated from the sponge Agelas dispar J. and identified as published before (Höller et al., 1999).

The fungus was cultivated at room temperature for two weeks in Erlenmeyer flasks, and $10 \mathrm{~mL}$ of this culture were transferred in the clean bench to three Erlenmeyer flasks of each medium $(100 \mathrm{~mL}$ each). The obtained extract is presented in Table II.

Table II. Weight of the ethyl acetate extracts produced by the media M1-M6 in mg per $100 \mathrm{~mL}$ medium. Each medium was treated in three flasks 1,2 and 3.

\begin{tabular}{lrrrrrrc}
\hline Flask No. & M1 & M2 & M3 & M4 & M5 & M6 & Control \\
\hline 1 & 11.4 & 23.6 & 7.0 & 18.9 & 10.4 & 26.8 & 21.2 \\
2 & 10.3 & 19.3 & 7.7 & 18.1 & 18.5 & 20.8 & 20.8 \\
3 & 9.3 & 17.7 & 10.3 & 17.2 & 14.6 & 22.5 & 22.3 \\
\hline
\end{tabular}

\section{LC/ESIMS conditions}

LC/ESIMS experiments were carried out on an API 2000 instrument. The column was a Macherey-Nagel Nucleodure 100-5 C18 HPLC column $(2 \mathrm{~mm} \times 125 \mathrm{~mm})$. The solvents were (A) 2 mmol aqueous $\mathrm{NH}_{4} \mathrm{Ac}$ and (B) $2 \mathrm{mmol} \mathrm{NH}_{4} \mathrm{Ac}$ in $\mathrm{MeOH}$, employing gradient elution from $\mathrm{H}_{2} \mathrm{O}$ / $\mathrm{MeOH} 9: 1$ to $\mathrm{MeOH}$ in $20 \mathrm{~min}$, followed by $10 \mathrm{~min}$ elution $\mathrm{MeOH}, 0.25 \mathrm{~mL} / \mathrm{min}, 10 \mu \mathrm{L}$ injecting volume of $1 \mathrm{mg} / \mathrm{mL}$ of the total extract. MS parameters were as follows: ionization mode, positive and negative mode; scan range, 100-700 amu; scan rate, $0.5 \mathrm{scan} / \mathrm{s}$; cone voltage, $20 \mathrm{eV}$.

\section{HPLC conditions for quantitative analysis}

The mobile phase was a gradient from $\mathrm{H}_{2} \mathrm{O} /$ $\mathrm{MeOH} 70: 30$ to $30: 70(\mathrm{v} / \mathrm{v})$ in $60 \mathrm{~min}$, then to $\mathrm{MeOH}$ in $40 \mathrm{~min}$, followed by $10 \mathrm{~min} \mathrm{MeOH}$, then back to $\mathrm{H}_{2} \mathrm{O} / \mathrm{MeOH} 70: 30$ in $5 \mathrm{~min}, 1 \mathrm{~mL} / \mathrm{min}$, to discriminate trichodermanone $\mathrm{A}(\mathrm{Rt}=58.5 \mathrm{~min})$, trichodermanone $\mathrm{C}(\mathrm{Rt}=52.8 \mathrm{~min})$, bislongiquinolide $(\mathrm{Rt}=44.7 \mathrm{~min})$, trichodimerol $(\mathrm{Rt}=$ $89.8 \mathrm{~min})$, and bisvertinol ( $\mathrm{Rt}=74.6 \mathrm{~min})$. The injecting volume of the ethyl acetate extract was $25 \mu \mathrm{L}$ of $2 \mathrm{mg} / \mathrm{mL}$ (methanol). All compounds were detected at $360 \mathrm{~nm}$. Before each elution the column was calibrated for $20 \mathrm{~min}$. The five compounds were detected in the total extract and con- 
firmed by comparison of their retention time with the retention time of pure compounds eluted by the same elution method.

The five compounds were obtained from a previous study (Neumann et al., 2007) and were purified by different HPLC methods. Five standard solutions $10,3,2,1,0.5 \mu \mathrm{g} / \mathrm{mL}$, and the stock solution $(1 \mathrm{mg} / \mathrm{mL})$ were injected to generate five-points calibration curves. For validation of these methods, each standard concentration was measured three times.

Abe N., Murata T., and Hirota A. (1998a), Novel DPPH radical scavengers, biosorbicillinol and demethyltrichodimerol, from a fungus. Biosci. Biotechnol. Biochem. 62, 661-666.

Abe N., Murata T., and Hirota A. (1998b), Novel oxidized sorbicillin dimers with 1,1-diphenyl-2-picrylhydrazyl-radical scavenging activity from a fungus. Biosci. Biotechnol. Biochem. 62, 2120-2126.

Andrade R., Ayer W. A., and Mebe P. P. (1992), The metabolites of Trichoderma longibrachiatum. Part 1. Isolation of the metabolites and the structure of trichodimerol. Can. J. Chem. 70, 2526-2535.

Höller U., König G. M., and Wright A. D. (1999), Three new metabolites from marine-derived fungi of the genera Coniothyrium and Microsphaeriopsis. J. Nat. Prod. 62, 114-118.

Höller U., Wright A. D., Matthée G. F., König G. M., Draeger S., Aust H. J., and Schulz B. (2000), Fungi from marine sponges: diversity biological activity and secondary metabolites. Mycol. Res. 104, 1354-1365.

König G. M. and Wright A. D. (1996), Marine natural products research: current directions and future potential. Planta Med. 62, 193-211.

König G. M. and Wright A. D. (1999), Trends in marine biotechnology. In: Drug Discovery from Nature, $1^{\text {st }}$

\section{Acknowledgement}

The author wishes to express his sincere thanks to Prof. G. M. König, Institute of Pharmaceutical Biology, University of Bonn, Germany, for the fungal strain. Thanks go to Prof. T. Okino (Faculty of Environmental Earth Science, Hokkaido University, Sapporo, Japan) for the HPLC analysis. This project is part of the DAAD project "Bioactive metabolites from marine-derived fungi", Project code 134.104401.212.

ed. (Grabley S. and Thiericke R. E., eds.). Springer, Berlin, pp. 180-187.

Neumann K., Abdel-Lateff A., Wright A. D., Kehraus S., Krick A., and König G. M. (2007), Novel sorbicillin derivatives, an unprecedented carbon skeleton from the sponge-derived fungus Trichoderma sp. Eur. J. Org. Chem. 2, 2268-2275.

Nicolaou K. C., Simonsen K. B., Vassilikogiannakis G., Baran P. S., Vidali V. P., Pitsinos E. N., and Couladouros E. A. (1999), Biomimetic explorations towards the bisorbicillinoids: total synthesis of bisorbicillinol, bisorbibutenolide, and trichodimerol. Angew. Chem. Int. Ed. 38, 3555-3559.

Nicolaou K. C., Vassilikogiannakis G., Simonsen K. B., Baran P. S., Zhong Y.-L., Vidali V. P., Pitsinos E. N., and Couladouros E. A. (2000), Biomimetic total synthesis of bisorbicillinol, bisorbibutenolide, trichodimerol, and designed analogues of the bisorbicillinoids. J. Am. Chem. Soc. 122, 3071-3079.

Persoon C. H. (1794), Disposito methodica fungorum in classes, ordines, familias et genera. In: Neues Magazin für Botanik (Römer J. J., ed.). Ziegler und Söhne, Zurich, pp. 63-128 (in German).

Sperry S., Samuels G. J., and Crews. P. (1998), Vertinoid polyketides from the saltwater culture of fungus Trichoderma longibrachiatum separated from a Haliclona marine sponge. J. Org. Chem. 63, 10011-10014. 